\title{
Method for Restricting Grid Single-Phase Short-Circuit Current
}

\author{
Liu Jingyan, Liu Wenying, and Li Xiaorong
}

\begin{abstract}
With the rapid growth of the grid structure and voltage level, some $500 \mathrm{kV}$ transformer substations' $220 \mathrm{kV}$ side of the single-phase short-circuit current level is so large that it has a bad impact on grid stability. To solve the problems, the main reason of the growth of single-phase short-circuit current is analyzed, and the method of main transformer neutral grounding via low resistance is proposed and the mechanism of the measure is analyzed. Simulation analysis with the Power System Analysis Software Package (PSASP) shows that the method of main transformer neutral grounding via low resistance can effectively suppress the single-phase short-circuits current.
\end{abstract}

Index Terms-Single-phase short-circuit current, zero sequence impedance, autotransformer, neutral grounding.

\section{INTRODUCTION}

With the rapid development of the construction of power grid, the grid internally has become much closer and grid short-circuit current level continues to rise. Some $500 \mathrm{kV}$ substation $220 \mathrm{kV}$ side bus single-phase short-circuit current level is larger than the three-phase short-circuit current, so that the choice of equipment becomes much more difficult. Therefore, one of the hot topics is the current control method of single-phase short-circuit current. Replace the $500 \mathrm{kV}$ auto-transformer to non-auto-transformer can increase the system's zero-sequence impedance and reduce the single-phase short-circuit current, but it's not economic and feasible for the substation that has been put into[1]-[4]; reduce substation near power plants step-up transformer high-pressure side of the neutral grounding number of units is easy to achieve, but it will have little effect if the power plant is not a major source of short-circuit current; autotransformer run in the $220 \mathrm{kV}$ side with separation in order to reduce $220 \mathrm{kV}$ side of the short-circuit current, but this method requires the bus section, a larger investment, and reduces the power supply reliability and stability[5].

Based on the mechanism of single-phase short-circuit current, the major reason for single-phase short-circuit current's high level is analyzed, proposed the method that $500 \mathrm{kV}$ autotransformer neutral grounding by small reactance. This method without grid restrictions, has great promotion, avoids replacing a large number of the switch of complex work and a waste of money, can bring good social and economic benefits.

Manuscript received October 18, 2012; revised November 23, 2012

Liu Jingyan and Liu Wenying are with the School of Electrical and Electronic Engineering, North China Electric Power University, 102206 , Beijing, China (e-mail: tommy.2909@hotmail.com)

Zheng Wei is with Electric Power Research Institute of Gansu Provincial Power Company.

\section{THEORETICAL ANALYsis}

\section{A. The Reason that Single-Phase Short-Circuit Current is Greater than the Three-Phase Short-Circuit Current}

Fault boundary conditions: assume that A phase to ground, the boundary equation at the short-circuit point is $\breve{U}_{k A}=0$, expressed in symmetrical components:

$$
I_{k A 0}=I_{k A 1}=I_{k A 2} \quad \dot{U}_{k A}=\dot{U}_{k A 1}+\dot{U}_{k A 2}+\dot{U}_{k A 0}=0
$$

So the single-phase ground fault short-circuit current is calculated as follows :

$$
\cdot I^{(1)}{ }_{K}=I_{A}=\frac{3 E_{A}}{Z_{1 \Sigma}+Z_{2 \Sigma}+Z_{0 \Sigma}}
$$

Three-phase short-circuit current calculation formula is $I^{(3)}{ }_{K}=\frac{E_{\mathrm{A}}}{Z_{1 \Sigma}}$ [6]. After comparing the two formulas, the comparison of single-phase short-circuit current and three-phase short-circuit current size is actually compared the size between $2 Z_{1 \Sigma}$ and $Z_{2 \Sigma}+Z_{0 \Sigma}$. To facilitate discussion, the article assumes that the short circuit point away from power, assuming that the positive sequence impedance equal to the negative sequence impedance, then:

$$
\frac{I^{(1)}{ }_{K}}{I^{(3)}{ }_{K}}=\frac{3 Z_{\Sigma_{1}}}{Z_{\Sigma_{1}}+Z_{\Sigma_{2}}+Z_{\Sigma_{0}}}=\frac{3}{2+\frac{Z_{\Sigma_{0}}}{Z_{\Sigma_{1}}}}
$$

When $Z_{\Sigma 0}$ is less than $Z_{\Sigma}$, the single-phase short-circuit current is greater than the three-phase short-circuit current. Most of the main transformers in the $500 \mathrm{kV}$ and $220 \mathrm{kV}$ substations use the autotransformer while the neutral of the autotransformer must be grounded, which makes too many zero-sequence equivalent network in parallel, resulting in zero sequence impedance is too small and single-phase short-circuit current is too large [7]. If the $500 \mathrm{kV}$ autotransformer neutral point grounded by low reactance, it can increase the zero sequence impedance of the system to suppress the single-phase short-circuit current in system.

\section{B. The Mechanism of the Transformer Neutral Point Grounded by Low Reactance Limit of Single-Phase Short-Circuit Current}

Fig. 1 is the autotransformer with neutral point grounding by low reactance and its zero sequence equivalent networks. Set up a potential difference between the secondary side of the end point and the neutral point of the known value is $U_{\text {In }}$ and $U_{\text {IIn }}$. Neutral point potential is $U_{\mathrm{n}}, U_{\mathrm{n}}=0$ when the neutral point directly to ground. Converted to the potential difference 
between the end of the primary and secondary windings is

$$
U_{I n}-U_{I I n} \times \frac{U_{I N}}{U_{I I N}}
$$

$U_{\text {In }}$ and $U_{\text {IIn }}$ is primary and secondary rated voltage. Therefore, converted to primary side of the equivalent zero-sequence reactance is

$$
x_{\mathrm{I}-\mathrm{II}}^{\prime}=x_{\mathrm{I}-\mathrm{II}}+3 x_{n}\left(1-\frac{\mathrm{U}_{\mathrm{IN}}}{\mathrm{U}_{\mathrm{IIN}}}\right)^{2}
$$

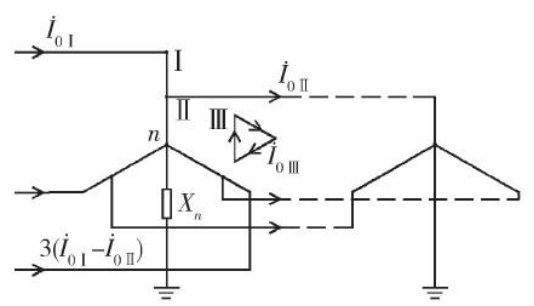

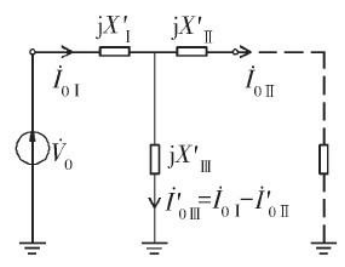

Fig. 1. Autotransformer with neutral reactance grounding and the equivalent network of its zero-sequence

In addition to the above III winding off the $X^{\prime}{ }_{\text {I-II }}$, you can list the II loop open, converted to I side of the III side between the zero-sequence reactance $X^{\prime}{ }_{\mathrm{I}-\mathrm{III}}=X_{\mathrm{I}-\mathrm{II}}+3 X_{\mathrm{n}}$. Side I of the winding disconnect, zero-sequence reactance converted to side I of the side II, III is

$$
x_{\mathrm{II}-\mathrm{III}}^{\prime}=x_{\mathrm{IIIIII}}+3 x_{n}\left(\frac{\mathrm{U}_{\mathrm{IN}}}{\mathrm{U}_{\mathrm{IIN}}}\right)^{2}
$$

Seeking three-winding transformer winding equivalent reactance formula, can obtain the star zero sequence equivalent circuit converted to the high side of the reactor[6]:

$$
\begin{aligned}
& x_{\mathrm{I}}^{\prime}=\frac{1}{2}\left(x_{\mathrm{I}-\mathrm{II}}^{\prime}+x_{\mathrm{I}-\mathrm{III}}^{\prime}-x_{\mathrm{II}-\mathrm{III}}^{\prime}\right)=x_{\mathrm{I}}+3 x_{\mathrm{n}}\left(1-\frac{\mathrm{U}_{\mathrm{IN}}}{\mathrm{U}_{\mathrm{IIN}}}\right) \\
& x_{\mathrm{II}}^{\prime}=\frac{1}{2}\left(x_{\mathrm{I}-\mathrm{II}}^{\prime}+x_{\mathrm{II}-\mathrm{III}}^{\prime}-x_{\mathrm{I}-\mathrm{III}}^{\prime}\right)=x_{\mathrm{II}}+3 x_{\mathrm{n}} \frac{\left(\mathrm{U}_{\mathrm{I} \mathrm{N}}-\mathrm{U}_{\mathrm{II} \mathrm{N}}\right) \mathrm{U}_{\mathrm{I} \mathrm{N}}}{\mathrm{U}_{\mathrm{II} \mathrm{N}}^{2}} \\
& x_{\mathrm{III}}^{\prime}=\frac{1}{2}\left(x_{\mathrm{I}-\mathrm{III}}^{\prime}+x_{\mathrm{II}-\mathrm{III}}^{\prime}-x_{\mathrm{I}-\mathrm{II}}^{\prime}\right)=x_{\mathrm{III}}+3 x_{\mathrm{n}} \frac{\mathrm{U}_{\mathrm{IN}}}{\mathrm{U}_{\mathrm{IIN}}}
\end{aligned}
$$

The above equation analysis shows that, if $X_{\mathrm{n}}=0$, that is the transformer neutral point grounding. As the pressure side reactance is often close to zero, so the extensive use of autotransformer cause $500 \mathrm{kV}$ substation voltage side of the zero-sequence reactance is very small, resulting in single-phase short-circuits current in the autotransformer. After the installation of low reactance in the neutral point, $X_{\mathrm{n}}$ is not zero, by equation (1), $X^{\prime}{ }_{\mathrm{I}}, X^{\prime}{ }_{\mathrm{II}}, X^{\prime}{ }_{\mathrm{III}}$ has increased. Known by the circuit principle, $X_{\mathrm{n}}$ exists only in the zero-sequence networks, so $X^{\prime}{ }_{\mathrm{I}}, X^{\prime}{ }_{\mathrm{II}}, X^{\prime}{ }_{\mathrm{III}}$ is the per unit value of main transformer zero sequence impedance and positive sequence impedance. Therefore, the main transformer neutral point install low reactance can effectively reduce the system's single-phase short-circuit current and does not change the value of the positive sequence impedance, and therefore does not change the size of three-phase short-circuit current, and does not affect the normal operation of the network loss [8].

\section{NUMERICAL EXAMPLE}

Simulation of the 2009 regional power grid load data, for example, use the "Power System Analysis Software Package (PSASP)", the calculation is not based on the power flow, the generators take $\mathrm{E}=1 \angle 0^{\circ}$ (p.u.), ignoring the impact of the load. Calculated that the system short-circuit current levels, the grid in 2009, 17 substations $220 \mathrm{kV}$ bus single-phase short-circuit current exceeds the three-phase short-circuit current, such as Shunyi $500 \mathrm{kV}$ substation $220 \mathrm{kV}$ side of the single-phase short-circuit current $51.01 \mathrm{kA}$, three-phase short-circuit current $47.87 \mathrm{kV}$. Now select the Shunyi $500 \mathrm{kV}$ substation transformer neutral point according to $5 \Omega$ differential cascaded small electric resistance, the following table for the Shunyi station connected to the $500 \mathrm{kV}$

\begin{tabular}{|c|c|c|c|c|c|}
\hline \multirow{2}{*}{$\begin{array}{l}\text { Shunyi } \\
500 \mathrm{kV} \\
\text { substatio } \\
\text { n } 220 \mathrm{kV}\end{array}$} & \multirow{2}{*}{$\begin{array}{l}\text { The single } \\
\text { phase short } \\
\text { circuit-curren } \\
\text { t }\end{array}$} & \multicolumn{4}{|c|}{$\begin{array}{l}\text { The short circuit-current after grounded by } \\
\text { reactance }\end{array}$} \\
\hline & & $5 \Omega$ & $10 \Omega$ & $15 \Omega$ & $20 \Omega$ \\
\hline bus1 & 39.56 & 35.22 & 33.84 & 32.29 & 31.49 \\
\hline bus2 & 51.01 & 41.79 & 37.82 & 35.19 & 33.48 \\
\hline
\end{tabular}
substation and the $220 \mathrm{kV}$ substation neutral point connected in series reactance before and after the short circuit current level.

TABLE I: 500KV TRANSFORMER NEUTRAL POINT AFTER THE CASCADED LOW REACTANCE TO THE 220KV BUS SiNGLE-PHASE SHORT-CIRCUIT CURRENT

According to the calculation results from Table 1, the $500 \mathrm{kV}$ substation $220 \mathrm{kV}$ side of the bus single-phase short-circuit current exceeds its three-phase short-circuit current, a larger decline in the single-phase short-circuit current level after its main transformer neutral point cascaded the $5 \Omega$ small reactance. Installation of the reactor, the single-phase short-circuit current dropped 9.22kA, a drop of $18.07 \%$, it has limited the $220 \mathrm{kV}$ side of the single-phase short-circuit current under the three-phase short-circuit current.

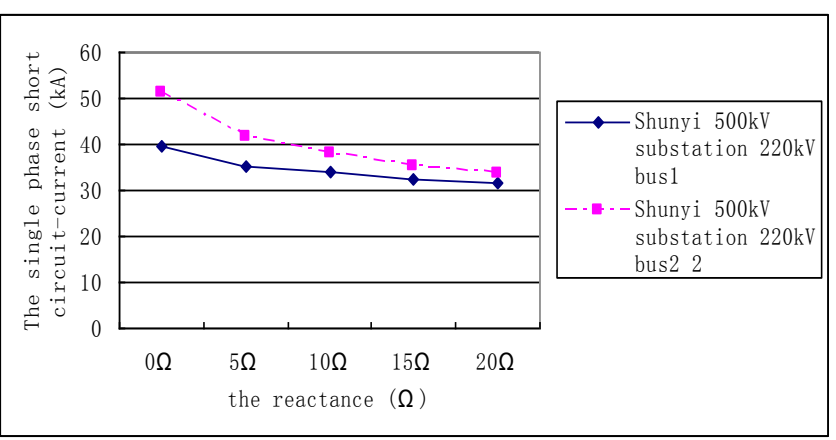

Fig. 2. 220kV side of the single-phase short-circuit current after neutral point of the $500 \mathrm{kV}$ substation by low reactance to ground

Known from Fig. 2, when the installation of low reactance 
to the resistance is more than $15 \Omega$, the neutral point of transformer in series small reactance $220 \mathrm{kV}$ single-phase short-circuit current limit the effect of saturation, the increase in electrical resistance to the $220 \mathrm{kV}$ side of the single-phase short-circuit current limit. The effect has been obvious. In the case of single-phase short circuit occurs, the series with the transformer neutral point small reactor will result in the offset voltage of the transformer neutral point, is likely to endanger the neutral insulation [9]. To limit the transformer neutral point of over-voltage, neutral point can be equipped with $\mathrm{ZnO}$ arresters; common protection equipment can meet to select the quick, sensitive requirements.

In the case of single-phase short circuit occurs, the series with the transformer neutral point small reactor will result in the offset voltage of the transformer neutral point, is likely to endanger the neutral insulation [10]. To limit the transformer neutral point of over-voltage, neutral point can be equipped with $\mathrm{ZnO}$ arresters, common protection equipment can meet to select the quick, sensitive requirements.

\section{CONCLUSION}

After the above analysis and calculation verification, we have the following main conclusions:

$500 \mathrm{kV}$ substation neutral point to ground by $5 \Omega$ electrical resistance, can effectively inhibit the $220 \mathrm{kV}$ side of the single-phase short-circuit current, and limit the single-phase short-circuit current under the three-phase short-circuit current.

According to Fig. 3, with the series reactance value increases in the $500 \mathrm{kV}$ substation, restrictions on the $220 \mathrm{kV}$ side of the single-phase short-circuit current is saturated. Therefore, the series 5-10 $\Omega$ of reactance is more appropriate for individual substations for which single-phase short-circuit current is too large. The series reactance will increase to $15-20 \Omega$.

Drawn from the above analysis, the single-phase short-circuit current size can be limited under the three-phase short-circuit current after taking the autotransformer neutral point grounded by low reactance. According to situation and purpose of limiting reactance, resistance can choose between $5-15 \Omega$.

\section{ACKNOWLEDGEMENT}

Project Supported by State Grid Corporation of China (2011103004).
Project Name: The Key Research Program Supported by State Grid Corporation of China

\section{REFERENCES}

[1] L. Jiang and Z. Q. Wang, "Impact of using $500 \mathrm{kV}$ and $220 \mathrm{kV}$ autotransformers to the single-phase short circuit current," Power System Protection and Control, vol. 36, no.17, pp. 108-116, 2008.

[2] G. Q. Li, Power systems transient analysis, Beijing: China Electric Power Press, 2007, vol. 5, pp. 66-67.

[3] H. J. Liu and S. Y. Chen, "500 kV the Guancheng substation limit single-phase short-circuit current measures," Rural Electrification, vol. 1, pp. 31-33, 2011.

[4] J. Yuan, W. Y. Liu, and M. Q. Dong, “Application of measures limiting short circuit currents in northwest China power grid," Power System Technology, vol. 31, no. 18, pp. 42-45, 2007.

[5] H. Li, H. Huang, and Q. Zhang "Study of limiting single phase ground short-current in Jiangsu power grid," Jiangsu Electrical Engineering, vol. 39, no.1, pp. 19-21, 2009.

[6] H. Chen, Power system steady-state analysis, Beijing: China Electric Power Press, 2007, vol. 4, pp. 45-46.

[7] H. Tian, Q. Wang, and F. Zhu, "Comparative studyof short-circuit current calculation results based on PSASP software," Power System Protection and Control, vol. 38, no. 1, pp. 56-60, 2010.

[8] T. Y.Zhu, "Application of autotransformer neutral grounding by small reactance in $500 \mathrm{kV}$ power system," Power System Technology, vol. 23, no. 4, pp. 15-18, 1999.

[9] Y. Z. Cheng and Y. J. Ye, "Application study of installing small reactors on neutral points of $500 \mathrm{kV}$ autotransformers," East China Electric Power, vol. 34, no. 11, pp. 59-61, 2006.

[10] J. F. Liang, W. Y. Liu, and C. Liang, "Analysis of limiting effect of 500 $\mathrm{kV}$ autotransformer neutral grounding by small reactance on ground short-circuit current," Power System Protection and Control, vol.13, no. 39, pp. 96-99, 2011.

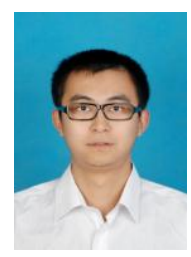

Liu Jingyan was born in Baoji, Shannxi, China in 1989, He graduate from North China Electric Power University. And he received the Bachelor of Engineering from North China Electric Power University in 2011, Beijing, China. Now he is doing research on the operation and control of power system analysis.

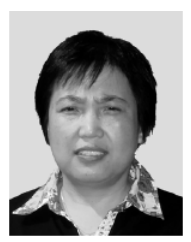

Liu Wenying is Professor of School of Electrical and Electronic Engineering, North China Electric Power University. Her research interests are power system analysis and control, power system intelligent scheduling.

Li Xiaorong is currently working at North China Electric Power Research Institute, whose research direction is power system analysis and control 